\title{
Evaluation of Cardiac Remodeling After Surgical Closure of Atrial Septal Defect in Different Age Groups
}

\author{
SMG Saklayen', Laila Akter Zahan ${ }^{2}$, Jubayer Ahmad ${ }^{3}$, Mohammad Armane Wadud $^{4}$, Tarana Fariah Monalisa ${ }^{5}$, \\ Rezwanul Hoque ${ }^{6}$, Ibrahim Khalilullah ${ }^{7}$
}

\section{ABSTRACT}

Background \& objective: Cardiac remodeling manifested clinically as changes in size, shape and function of the heart. The extent of remodeling depends on initial morphological changes. So the time at which the surgical correction of atrial septal defect (ASD) done is important. Apparently surgical outcome and remodeling is better at earlier age in comparison to adult age. The aim of this study was to find whether surgical correction of ASD is beneficial at younger age (up to 18 years) in comparison to adult age (above 18 years).

Methods: This prospective cohort study was carried out on a total of 70 patients who underwent surgical closure of atrial septal defect over a period of twenty three months (23) months (from February 2013 to December 2014) in the Department of Cardiac Surgery, Bangabandhu Sheikh Mujib Medical University, Dhaka. The recruited patients were divided into two groups - Group-A (comprised of $\leq 18$ years old patients) and Group-B (comprised of $>18$ years old patients) 35 patients in each. Condition of the heart was evaluated preoperatively by echocardiography and the result was compared with postoperative echocardiographic findings at follow-ups after 1 and 3 months after surgery.

Results: The comparison of echocardiographic parameters between baseline (preoperative) and those at 1 and 3 months after surgery in Group-A demonstrated that statistically significant remodeling occurred after $1^{\text {st }}$ month $(p<0.001)$ and it further improved at 3 months. In Group-B the comparison of echo parameters between baseline and at 1 month revealed that all the parameters responded significantly indicating that remodeling occurred well after 1 month. But the same parameters when compared between baseline and at months after repair revealed insignificant differences in all the parameters, except PWT indicating that remodeling that occurred at month 1 regressed at 3 months interval. Cardiac remodeling occurred in both groups, but the degree of remodeling between patients of early age (Group-A) and late age (Group-B) revealed that ASD repair at early age responded well with respect to all the echocardiographic variables of remodeling.

Conclusion: Cardiac remodeling occurs after surgical closure of atrial septal defect. But the degree of remodeling is better if the closure is done at earlier age (at or below 18 years).

Key words: Atrial Septal Defect, Cardiac Remodeling, Surgical Closure, Age etc.

\section{Authors' information:}

'Dr. SMG Saklayen, Assistant Professor and Associate Consultant, Department of Vascular Surgery, Ibrahim Cardiac Hospital and Research Institute 2 Dr. Laila Akter Zahan, Registrar and Specialist, Department of Vascular Surgery, Ibrahim Cardiac Hospital and Research Institute ${ }^{3}$ Dr. Jubayer Ahmad, Assistant Professor and Associate Consultant, Department of Vascular Surgery, Ibrahim Cardiac Hospital and Research Institute

${ }^{4}$ Dr. Mohammad Armane Wadud, Assistant Professor and Associate Consultant, Department of Cardiac Surgery, Ibrahim Cardiac Hospital and Research Institute

${ }^{5}$ Dr. Tarana Fariah Monalisa, Bangladesh Civil Service (Health), OSD, Director General Health

${ }^{6}$ Dr. Rezwanul Hoque, Professor and Chairman, Department of Cardiac Surgery, Bangabandhu Sheikh Mujib Medical University

${ }^{7}$ Dr. Ibrahim Khalilullah, Registrar and Specialist, Department of Cardiac Anesthesiology, Ibrahim Cardiac Hospital and Research Institute

Correspondence: Dr. SMG Saklayen, Phone:01552344915, email: saklayendmc@gmail.com 


\section{INTRODUCTION:}

An Atrial Septal Defect (ASD) represents a communication between the left and right atrium leading to left to right shunt. It makes up about $10 \%$ of all congenital heart diseases after delivery and up to $30-40 \%$ of heart defects diagnosed in patients aged over 40 years. ${ }^{1}$ The progression of this congenital defect to congestive cardiac failure follows the onset of pulmonary hypertension, arrhythmias, respiratory infections, and other cardiovascular disease. Hence, the defect is usually discovered when a patient presents with dyspnoea or palpitations or occasionally on routine medical examination. ${ }^{2}$ About $75 \%$ of adult patients with atrial septal defect show signs or symptoms of the disease in the third or fourth decade of life. Closure of most atrial septal defects is still the treatment of choice in children $\&$ young adults, because of the low surgical risk and good long-term outcome. Surgical management of atrial septal defect became a clinical reality in the 1940s. However, the beneficial result of closure in adults over 40 years of age remains controversial, primarily because, incomplete information exists regarding the natural history and the variables associated with survival beyond this age. ${ }^{3}$

Cardiac remodeling may be defined as genome expression, molecular, cellular and interstitial changes that are manifested clinically as changes in size, shape and function of the heart after cardiac injury. The myocyte is the major cardiac cell involved in the remodeling process. Other components involved are interstitium, fibroblasts, collagen and coronary vasculature. Relevant processes include in the remodeling are ischemia, cell necrosis \& apoptosis. ${ }^{4}$ Pathologic remodeling may occur with pressure overload (e.g., aortic stenosis, hypertension), volume overload (e.g., atrial septal defect, valvular regurgitation), or following cardiac injury (e.g., myocardial infarction). In each of these settings, remodeling may reveal transition from an apparently compensatory process to a maladaptive one. ${ }^{2}$

Measures to assess LV remodeling include heart size, shape and mass, ejection fraction, end-diastolic and end-systolic volumes and peak force of contraction. Although direct measurement of the size and shape of the heart might appear to be the most logical method of assessing the extent of remodeling, technical factors and differences of interpretation lead to variation in the results. For example, only $38 \%$ of hypertensive patients with anatomic LV hypertrophy showed LV hypertrophy when assessed on M-mode echocardiography. ${ }^{4}$ The extent of cardiac remodeling after surgical correction depends on initial morphological changes attributed to the disease process itself. So the age at which surgical corrections are made have important bearings on the remodeling process itself.

\section{METHODS:}

This prospective cohort study was carried out on a total of 70 patients (ranging from 5 - 50 years) who underwent surgical closure of atrial septal defect over a period of twenty three months (February 2013 to December 2014) in the Department of Cardiac Surgery, Bangabandhu Sheikh Mujib Medical University, Dhaka. Informed written consent was taken from each patient before enrollment. Patients with isolated ASD (Septum primum, Septum secondum, Sinous Venosus type of ASD) were included. However, patients of ASD with associated lesion, systemic disease such as end stage renal disease, hepatic failure, respiratory failure and ASD with Eisenmenger's syndrome were excluded. Detailed history, clinical examination \& relevant investigation reports of all patients were recorded on the data-sheet. The patients were divided into two groups - Group-A (comprised of $\leq 18$ years old patients) \& Group-B (comprised of $>18$ years old patients) 35 patients in each group. Condition of the heart was evaluated preoperatively by echocardiography and the result was compared with postoperative echocardiographic findings at follow-ups after 1 and 3 months of surgery. The echocardiographic variables used to evaluate the cardiac remodeling (morphological and functional outcome of heart) were LA (Left Atrium), IVST (Interventricular Septal Thickness), PWT (Posterior Wall Thickness), LVIDd (Left Ventricular Internal Diameter at End-Diastole), LVIDs (Left 
Ventricular Internal Diameter At End-Systole), EF (Ejection Fraction), FS (Fractional Shortening).

All patients underwent median sternotomy followed by surgical closure of ASD. All statistical analyses were performed using SPSS 22.0 statistical package. While continuous data were expressed as mean \pm SD \& were compared between groups using Unpaired t-Test, qualitative data presented as frequency (percentage) and were compared between groups using Chi-square $\left(\chi^{2}\right)$ Test. All analyses were done at $5 \%$ level of significance and $p$-value $<0.05$ was considered significant.

\section{RESULT:}

The mean ages of the patients of Group-A and Group-B were $12.1 \pm 3.4$ and $30.7 \pm 6.8$ years respectively. Of the 35 patients in Group-A $22(62.9 \%)$ were male and $13(37.1 \%)$ were female, while in Group-B, out of 35 patients, $18(51.4 \%)$ were male and $17(48.6 \%)$ female. Majorities of the ASDs in Group-A (71.4\%) and Group-B (80\%) were septum secondum followed by septum primum and sinous venosus defect. The groups were almost identical in terms of type ASDs $(p=0.700)$ (Table I).

Table II shows mean diameter of LA, IVST, PWT, LVIDd, LVIDs, EF, FS at preoperative period and at 1 and 3 months following ASD repair. The comparison of these echocardiographic parameters between preoperative findings versus findings at 1 and 3 months revealed that statistically significant remodeling occurred after surgical correction $(p<$ 0.001). In Group-B the comparison between preoperative findings versus findings at 1 month demonstrated that all the parameters responded significantly. But the same parameters when compared between baseline and at 3 months after repair revealed insignificant differences in all the parameters except in PWT (Table III). Table IV shows the mean changes in LA diameter, LVIDd, LVIDS, IVST, PWT, EF, FS from preoperative period to 3 months between Group-A and Group-B. Comparison of degree of remodeling between Group-A and Group-B at 3 months revealed that Group-A responded well in all the variables of remodeling.
Table I. Comparison of type of type of ASDs between the two study groups

\begin{tabular}{|c|c|c|c|}
\hline \multirow[b]{2}{*}{$\begin{array}{l}\text { Baseline } \\
\text { characteristics* }\end{array}$} & \multicolumn{2}{|c|}{ Group } & \multirow[b]{2}{*}{$\mathrm{p}$-value } \\
\hline & $\begin{array}{c}\text { Group-A } \\
(n=35)\end{array}$ & $\begin{array}{c}\text { Group-B } \\
(n=35)\end{array}$ & \\
\hline \multicolumn{4}{|l|}{ Sex } \\
\hline Male & $22(62.9)$ & $18(51.4)$ & \multirow{2}{*}{0.334} \\
\hline Female & 13(37.1) & 17(48.6) & \\
\hline \multicolumn{4}{|l|}{ Types of ASD } \\
\hline Septum Secondum & $25(71.4)$ & $28(80.0)$ & \multirow{3}{*}{0.700} \\
\hline Septum Primum & $6(17.1)$ & $4(11.4)$ & \\
\hline Sinous Venosus & $4(11.4)$ & $3(8.5)$ & \\
\hline
\end{tabular}

Figures in the parentheses denote corresponding percentage. *Data were analyzed using Chi-square $\left(\chi^{2}\right)$ Test and were presented as $\mathbf{n}(\%)$.

Table II. Comparison of echocardiographic findings at preoperative, after 1 month and 3 months of operation in Group-A

\begin{tabular}{|l|c|c|c|c|c|c|}
\hline & \multicolumn{3}{|c|}{ Group-A } & \multicolumn{2}{c|}{$\begin{array}{c}\text { Statistical } \\
\text { Analysis (p-value) }\end{array}$} \\
\hline Variables & Preoperative & At 1 month & At 3 month & $\begin{array}{c}\text { Preoperative } \\
\text { vs. } \\
\text { at 1 month }\end{array}$ & $\begin{array}{c}\text { Preoperative } \\
\text { vs. }\end{array}$ \\
\hline LA (mm) & $30.43 \pm 2.59$ & $31.40 \pm 2.72$ & $29.20 \pm 4.14$ & $<0.001^{*}$ & $0.062 \mathrm{~ns}$ \\
\hline IVST (mm) & $8.83 \pm 1.42$ & $9.89 \pm 1.37$ & $8.54 \pm 1.74$ & $<0.001^{*}$ & $0.086 \mathrm{~ns}$ \\
\hline PWT (mm) & $9.06 \pm 1.30$ & $10.26 \pm 1.40$ & $8.97 \pm 1.25$ & $<0.001^{*}$ & $0.032^{*}$ \\
\hline LVIDd (mm) & $47.29 \pm 2.54$ & $48.46 \pm 2.67$ & $46.86 \pm 2.83$ & $<0.001^{*}$ & $0.062 \mathrm{~ns}$ \\
\hline LVIDs (mm) & $33.20 \pm 2.21$ & $34.37 \pm 2.21$ & $32.74 \pm 2.83$ & $<0.001^{*}$ & $0.081 \mathrm{~ns}$ \\
\hline EF (\%) & $65.00 \pm 3.13$ & $64.14 \pm 3.97$ & $65.31 \pm 7.12$ & $<0.013^{*}$ & $0.758 \mathrm{~ns}$ \\
\hline FS (\%) & $29.37 \pm 2.12$ & $41.64 \pm 4.65$ & $30.17 \pm 4.84$ & $<0.001^{*}$ & $0.268 \mathrm{~ns}$ \\
\hline
\end{tabular}

*Data were analyzed using Unpaired t-Test and were presented as mean \pm SD.

Table III. Comparison of echocardiographic findings at preoperative, after 1 month and 3 months of operation in Group-B

\begin{tabular}{|l|c|c|c|c|c|}
\hline $\begin{array}{l}\text { Echo } \\
\text { Variables }\end{array}$ & \multicolumn{3}{|c|}{ Group-B } & \multicolumn{2}{c|}{$\begin{array}{c}\text { Statistical } \\
\text { Analysis (p-value) }\end{array}$} \\
& Preoperative & At 1 month & At 3 month & $\begin{array}{c}\text { Preoperative } \\
\text { vs. } \\
\text { at 1 month }\end{array}$ & $\begin{array}{c}\text { Preoperative } \\
\text { at 1 month }\end{array}$ \\
\hline LA (mm) & $30.43 \pm 2.59$ & $31.40 \pm 2.72$ & $29.20 \pm 4.14$ & $<0.001^{*}$ & $0.062 \mathrm{~ns}$ \\
\hline IVST (mm) & $8.83 \pm 1.42$ & $9.89 \pm 1.37$ & $8.54 \pm 1.74$ & $<0.001^{*}$ & $0.086 \mathrm{~ns}$ \\
\hline PWT $(\mathrm{mm})$ & $9.06 \pm 1.30$ & $10.26 \pm 1.40$ & $8.97 \pm 1.25$ & $<0.001^{*}$ & $0.032^{*}$ \\
\hline LVIDd $(\mathrm{mm})$ & $47.29 \pm 2.54$ & $48.46 \pm 2.67$ & $46.86 \pm 2.83$ & $<0.001^{*}$ & $0.062 \mathrm{~ns}$ \\
\hline LVIDs (mm) & $33.20 \pm 2.21$ & $34.37 \pm 2.21$ & $32.74 \pm 2.83$ & $<0.001^{*}$ & $0.081 \mathrm{~ns}$ \\
\hline EF (\%) & $65.00 \pm 3.13$ & $64.14 \pm 3.97$ & $65.31 \pm 7.12$ & $0.013^{*}$ & $0.758 \mathrm{~ns}$ \\
\hline FS (\%) & $29.37 \pm 2.12$ & $41.64 \pm 4.65$ & $30.17 \pm 4.84$ & $<0.001^{*}$ & $0.268 \mathrm{~ns}$ \\
\hline
\end{tabular}

*Data were analyzed using Unpaired t-Test and were presented as mean \pm SD. 


\begin{tabular}{|c|c|c|c|c|}
\hline \multirow[b]{2}{*}{ Variables } & \multicolumn{2}{|c|}{ Group } & \multirow[b]{2}{*}{$\mathrm{t}$-value } & \multirow[b]{2}{*}{$p$-value } \\
\hline & $\begin{array}{l}\text { Group-A } \\
(n=35)\end{array}$ & $\begin{array}{c}\text { Group-B } \\
(n=35)\end{array}$ & & \\
\hline $\mathrm{LA}(\mathrm{mm})$ & $-2.09 \pm 0.88$ & $-1.23 \pm 2.17$ & -1.30 & $0.033^{*}$ \\
\hline LVIDd (mm) & $-4.20 \pm 1.53$ & $-0.43 \pm 1.31$ & -11.07 & $<0.001^{*}$ \\
\hline LVIDs(mm) & $-4.17 \pm 1.40$ & $-0.46 \pm 1.50$ & -10.69 & $<0.001^{*}$ \\
\hline IVST(mm) & $-1.97 \pm 0.95$ & $-0.29 \pm 0.96$ & -7.38 & $<0.001^{*}$ \\
\hline PWT(mm) & $-1.89 \pm 0.96$ & $-0.09 \pm 0.28$ & -10.60 & $<0.001^{*}$ \\
\hline $\mathrm{EF}(\%)$ & $5.40 \pm 2.68$ & $0.31 \pm 6.00$ & 4.58 & $<0.001^{*}$ \\
\hline $\mathrm{FS}(\%)$ & $3.43 \pm 1.87$ & $0.80 \pm 4.21$ & 3.38 & $0.001^{*}$ \\
\hline
\end{tabular}

Figures in the parentheses denote corresponding percentage. *Data were analyzed using Chi-square $\left(\chi^{2}\right)$ Test and were presented as $\mathbf{n}(\%)$.

\section{DISCUSSION:}

The comparison of echocardiographic parameters between baseline (preoperative) and those at $1 \&$ 3 months after surgery in Group-A demonstrated that statistically significant remodeling occurred after $1^{\text {st }}$ month $(p<0.001) \&$ it further improved at 3 months. In Group-B the comparison of echo parameters between baseline and at 1 month revealed that all the parameters responded significantly indicating that remodeling occurred well after 1 month. But the same parameters when compared between baseline and at 3 months after repair revealed insignificant differences in all the parameters, except in PWT indicating that remodeling that occurred at month 1 regressed at 3 months interval.

In a retrospective study, Oliver et $\mathrm{al}^{6}$ examined the outcome of early and late surgical repair of ASD in adults, as compared with the natural evolution of unoperated patients. Their study population comprised of 280 patients (mean age $40 \pm 18$ years, with youngest and the oldest patients) with non-restrictive ASD: 102 patients underwent surgery before the age of 25 years, 90 patients underwent surgery after the age of 25 years, and 88 unoperated patients were older than 25 years at the time of study.

In Group-A the mean diameter of left atrium at preoperative period was $28.3 \pm 4.0 \mathrm{~mm}$ which increased to $35.5 \pm 3.3 \mathrm{~mm}$ after $1^{\text {st }}$ month and then decreased to $26.2 \pm 3.9 \mathrm{~mm}$ after $3^{\text {rd }}$ month of postoperative period and in Group- $B$, the mean diameter of left atrium at preoperative period was $30.4 \pm 2.6 \mathrm{~mm}$ which increased to $31.4 \pm 2.7 \mathrm{~mm}$ after $1^{\text {st }}$ month and decreased to $29.2 \pm 4.1 \mathrm{~mm}$ after $3^{\text {rd }}$ month of postoperative period. LA size increased in the first month probably due to oedema, myocardial ishchaemia and effect of cardiopulmonary bypass. This finding of LA dimension is consistent with finding of Roberts et $\mathrm{al}^{5}$. They concluded that there was marked LA enlargement in patients with ASDs, suggesting that in addition to the known volume overload with resultant stretch of the right atrium, there is chronic stretch of the LA. Second, there were structural changes within the LA with loss of functioning myocardium. But according to Oliver et $\mathrm{al}^{6}$, the size of the left atrium is much smaller in patients who undergo surgery before the age of 25 years than in those who undergo surgery after the age of 25 and in those who do not undergo surgery. The contribution of volume overload to the increase in size of the left atrium does not appear to be important, as those patients who underwent closure of the ASD after the age of 25 years had the same or even greater left atrial size than the patients who did not undergo surgery. In group $A$, the interventricular septal thickness at preoperative period was $8.5 \pm$ $1.2 \mathrm{~mm}$ which increased to $10.4 \pm 0.8 \mathrm{~mm}$ after $1^{\text {st }}$ month and decreased to $6.5 \pm 1.4 \mathrm{~mm}$ after $3^{\text {rd }}$ month of postoperative period and in group $B$, the interventricular septal thickness at preoperative period was $8.8 \pm 1.4 \mathrm{~mm}$ which increased to $9.9 \pm$ $1.4 \mathrm{~mm}$ after $1^{\text {st }}$ month and decreased to $8.5 \pm 1.7$ $\mathrm{mm}$ after $3^{\text {rd }}$ month of postoperative period.

In group $A$, the posterior wall thickness at preoperative period was $8.11 \pm 1.59 \mathrm{~mm}$ which increased to $9.6 \pm 1.5 \mathrm{~mm}$ after $1^{\text {st }}$ month and decreased to $6.2 \pm 1.8 \mathrm{~mm}$ after $3^{\text {rd }}$ month of postoperative period and in group $\mathrm{B}$, the PWT at baseline was $9.1 \pm 1.3 \mathrm{~mm}$ which increased to 10.2 $\pm 1.4 \mathrm{~mm}$ after $1^{\text {st }}$ month and decreased to $8.9 \pm 1.2$ $\mathrm{mm} 3^{\text {rd }}$ month after repair. The LVIDd at preoperative period was $41.3 \pm 3.2 \mathrm{~mm}$ which changed to $45.9 \pm$ 3.2 and $37.1 \pm 3.6 \mathrm{~mm}$ after $1^{\text {st }}$ and $3^{\text {rd }}$ month postoperatively respectively, while the same parameter in Group-B, the LVIDd at preoperative 
period was $47.3 \pm 2.5 \mathrm{~mm}$ which enlarged to $48.4 \pm$ $2.7 \mathrm{~mm}$ after $1^{\text {st }}$ month and decreased to $46.8 \pm 2.8$ $\mathrm{mm}$ after $3^{\text {rd }}$ month postoperatively. At first month of postoperative period LVIDd probably increased due to postoperative myocardial ishchaemia, and oedematous changes resulting from manipulation of the heart. Komar et $\mathrm{al}^{7}$ showed that LVIDd reduces insignificantly from baseline value, 49.9 to $47.3 \mathrm{~mm}$ at $1^{\text {st }}$ month, $45.9 \mathrm{~mm}$ at 6 month. According to Thilén et $\mathrm{al}^{8}$ the left ventricle increased significantly in size after closure, whether measured as an area or as a dimension (LVIDD). However, closure did not affect left atrial size. Komar et $\mathrm{al}^{7}$ observed that LVIDs increases from baseline value, 35.4 to 38.5 $\mathrm{mm}$ at $1^{\text {st }}$ month and then reduces to $36.5 \mathrm{~mm}$ at 6 months with no significant changes from baseline to 6 months.

In group $A$, the ejection fraction at preoperative period was $62.9 \pm 2.6$ percent which decreased to $53.4 \pm 10.9$ percent after $1^{\text {st }}$ month and increased to $68.4 \pm 3.8$ percent after $3^{\text {rd }}$ month postoperatively and in Group-B, the ejection fraction at preoperative period was $65.0 \pm 3.1$ percent which decreased to $64.1 \pm 3.9$ percent after $1^{\text {st }}$ month $\&$ increased to $65.3 \pm 7.1$ percent after $3^{\text {rd }}$ month postoperatively. According to Komar et $\mathrm{al}^{7} \mathrm{EF}$ reduces from $60.4 \%$ at baseline to $59.4 \%$ at $1^{\text {st }}$ month postoperatively but again increases at 6 month postoperatively. The fractional shortening in Group-A at preoperative period was $28.5 \pm 1.9$ percent which decreased to $22.9 \pm 1.9$ percent after $1^{\text {st }}$ month and to $31.9 \pm 278$ percent after $3^{\text {rd }}$ month of repair. The same variable in Group-B, at preoperative period was $29.3 \pm 2.1$ percent which increased to $41.6 \pm 5.6$ percent after $1^{\text {st }}$ month and again decreased to $30.2 \pm 4.8$ percent after $3^{\text {rd }}$ month of postoperative period compared to its preoperative figure.

In group $A$, the comparison between preoperative findings versus 1 month and preoperative versus 3 months was statistically significant in case of LA, IVST, PWT, LVIDd, LVIDs, EF and FS. In group B, the comparison between preoperative findings versus 1 month was statistically significant in case of LA, IVST, PWT, LVIDd, LVIDs, EF and in FS. But the comparison between preoperative findings versus 3 months was insignificant in case of LA, IVST, LVIDd,
LVIDs, EF and in FS. Comparison of degree of remodeling between patients of early age (Group-A) and late age (Group-B) revealed that ASD repair at early age respond well with respect to all the echocardiographic variables of remodeling.

\section{CONCLUSION:}

This study observed that cardiac remodeling occurs after surgical closure of atrial septal defect at any age but the degree of remodeling was better patients less than 18 years, compared to that in 18 or more than 18 years old.

\section{REFERENCE:}

1. Suchon E, Tracz W, Podolec P, Sadowski J. Atrial septal defect in adults: the influence of age and haemodynamic parameters on the results of surgical repair. Kardioligia Polska 2006;64:470-76.

2. Ghosh S, Chatterjee S, Black E, Firmin RK. Surgical closure of atrial septal defects in adults: effect of age at operation on outcome. Heart 2002;88:485-87.

3. Attie F, Rosas M, Granasos N, Zabal C, Buendia A, Calderon J. Surgical Treatment for Secundum Atrial Septal Defects in Patients 40 Years Old: A Randomized Clinical Trial. American Journal of Cardiology 2001; 38:2035-42.

4. Cohn JN, Ferrari R, Sharpe N. Cardiac remodelingconcepts and clinical implications: a consensus paper from an international forum on cardiac remodeling. Behalf of an International Forum on Cardiac Remodeling. Journal of American college of cardiology 2000;35:569-78.

5. Roberts KC, John B, Worthley SG, Brooks AG, Stiles MK, Lau $\mathrm{DH}$ et al. Left atrial remodeling in patients with atrial septal defects. Heart Rhythm 2009;6:1000-06.

6. Oliver JM, Gallergo P, Gonzalez AE, Benito F, Sanz E, Aroca A et al. Surgical Closure of Atrial Septal Defect Before or After the Age of 25 Years. Comparison with the Natural History of Unoperated Patients. Revista Espanola de cardiologia 2002;55:953-61.

7. Komar M, Przewlocki T, Olszowska M, Sobien B, Podolec P. The benefit of atrial septal defect closure in elderly patients. Clinical Interventions in aging 2014;47: 1103-07.

8. Thilén $U$, Persson S. Closure of atrial septal defect in the adult. Cardiac remodeling is an early event. International Journal of cardiology 2006;108:370-75. 